\title{
LOS DESEMPLEADOS EN LA UNIDAD FAMILIAR: PROVEEDORES Y DEPENDIENTES
}

\author{
Félix Moral
}

Centro de Investigaciones Sociológicas

\begin{abstract}
RESUMEN
El objetivo de esta nota de investigación es el establecimiento de una tipología de la población desempleada en España atendiendo a dos dimensiones esenciales para afrontar el problema: la posición de los desempleados ante los mecanismos de protección generados por el Estado del Bienestar y el rol desempeñado por el desempleado en el seno de la unidad familiar. El resultado es una clasificación de los desempleados entre proveedores, coproveedores, desamparados y dependientes, que pone de manifiesto una patente desigualdad en el acceso a los mecanismos de protección social. La conclusión que cabe extraer es que el modelo de Estado del Bienestar imperante en la sociedad española cumple una función subsidiaria del que sigue siendo el principal mecanismo de solidaridad social: la institución familiar.
\end{abstract}

A lo largo del año 1996, el Instituto Nacional de Empleo (INEM) se planteó la necesidad de realizar, en colaboración con el Centro de Investigaciones Sociológicas (CIS), un estudio sobre las condiciones de vida de los desempleados españoles, con el fin último de analizar la adecuación de los sistemas de protección social al desempleo que estaban en vigor en ese momento a las necesidades reales de la población desempleada. Entre noviembre y diciembre de ese mismo año se llevó a cabo, finalmente, el trabajo de campo de una encuesta a una muestra de 4.658 desempleados representativos de los inscritos entonces en el INEM como demandantes de empleo. Pasado el período de

\section{Reis}


embargo (un año) al que se comprometió el CIS con el INEM, durante el cual los datos permanecen como propiedad exclusiva de este último organismo, los resultados de la encuesta pasan a formar parte del Banco de Datos del CIS, quedando a disposición de los investigadores interesados en la cuestión ${ }^{1}$.

\section{HIPÓTESIS DE PARTIDA}

En la sociedad española actual, agobiada por el gravísimo problema del desempleo, la familia constituye el primero y principal mecanismo de protección social que permite afrontar las situaciones generadas por el desempleo, cubriendo las carencias que se advierten en el modelo de protección desarrollado por el incipiente Estado del Bienestar. Como señala un conocido investigador del papel de la familia, "aunque en España los científicos sociales, y los políticos, no suelen percibir las importantes funciones redistributivas y de protección social que sigue desempeñando la familia en la sociedad moderna, éstas adquieren toda su notoriedad cuando se dan altas tasas de paro. La familia proporciona entonces una red de apoyo social básica para evitar la desintegración psicológica del parado en una sociedad fundada en el trabajo" (Iglesias de Ussel, 1995: 191). En este mismo sentido, otro autor define a la familia de forma contundente y expresiva como el «sistema de seguridad social tradicional» (Garrido, 1993: 158).

Para otro experto en cuestiones del mercado de trabajo, "no se suele prestar atención a la incidencia que tiene el fenómeno del paro en las familias. Ello constituye innegablemente una laguna importante en los análisis del paro, pues la incidencia social del fenómeno es mucho mejor apreciada si se adopta un enfoque familiar que uno estrictamente individual» (Toharia, 1993: 316). Si esto es así, de lo que no parece haber ninguna duda, resulta evidente que para analizar la situación social y las condiciones de vida de la población desempleada se hace imprescindible empezar por el estudio de su situación familiar y, dentro del análisis de esta situación, por la consideración del rol que la persona en situación de desempleo desempeña en el seno del hogar familiar. Dicho de otro modo, no se pueden conocer las condiciones de vida de los desempleados si no se conocen las características de su entorno vital, entorno que en la inmensa mayoría de los casos es la familia.

El papel especialmente relevante de la familia como mecanismo de protección social tiene que ver con la propia forma que adopta el Estado del Bienestar en una sociedad como la española. En la ya reconocida tipología de EspingAndersen, el modelo español de Estado del Bienestar se inscribiría, junto a la mayor parte de los países europeos continentales, en el modelo denominado «corporativista» o "católico-conservador» o, simplemente, «continental», frente

1 Debo dejar constancia de mi agradecimiento a la dirección del Centro de Investigaciones Sociológicas por la autorización para utilizar estos datos, correspondientes al estudio n. ${ }^{\circ} 2226$, así como por las facilidades otorgadas para reexplotarlos. 
al modelo «liberal» característico de los países anglosajones y al «socialdemócrata» que predomina en los países escandinavos. Según este autor, los regímenes "continentales» de Estado del Bienestar se caracterizarían, precisamente, por estar "fuertemente comprometidos con la conservación de la familia tradicional» y por concebir la seguridad social a partir de un principio de subsidiariedad que consiste en que "el Estado intervendrá solamente cuando se acabe la capacidad de la familia para atender a sus miembros" (Esping-Andersen, 1993: 48).

Para dotar a la familia de esta capacidad para atender a sus miembros se hace necesario establecer un sistema de protección que está especialmente orientado hacia el varón proveedor de los recursos, a quien se garantiza la estabilidad en el empleo. Ello genera una rigidez en el mercado de trabajo que provoca su segmentación entre un núcleo de trabajadores estables con un alto grado de protección social (los varones casados, a los que se presuponen responsabilidades familiares) y otro mercado precario con un alto grado de inestabilidad y bajos niveles de protección social, que incluye fundamentalmente a las mujeres y los jóvenes (Esping-Andersen, 1995: 21-22). Una de las consecuencias de esta segmentación del mercado de trabajo entre un núcleo y una periferia («insider-outsider» labor markets) es que la población desempleada se encuentra también segmentada entre un núcleo protegido, constituido principalmente por los desempleados varones con responsabilidades proveedoras, y una periferia de desempleados que no son cubiertos por los mecanismos sociales de bienestar y cuyas necesidades quedan exclusivamente al cuidado de las familias.

\section{LA SITUACIÓN FAMILIAR DE LOS DESEMPLEADOS}

El primer dato que viene a corroborar la importancia que tiene la institución familiar en el análisis de las condiciones de vida de los desempleados en España lo da el hecho de que el 96 por 100 de los desempleados inscritos en el INEM vive en un entorno familiar, de manera que constituye una minoría apenas testimonial en el conjunto de la población la proporción de los desempleados que viven solos (el 3 por 100) o que conviven con otras personas (en una pensión, en un piso compartido) con las que no les unen lazos familiares (1 por 100).

Contra lo que pudiera pensarse a priori, no son precisamente los desempleados más jóvenes los que viven fuera de un entorno familiar — solteros emancipados del hogar paterno-, sino que, por el contrario, son los de más edad quienes en mayor medida — aunque siempre de manera extremadamente minoritaria - viven solos o en entornos no familiares. El perfil característico de esta minoría de desempleados que permanece a la intemperie, desprotegida del paraguas que, ante la situación de desempleo, representa en una sociedad como la española la institución familiar, queda reflejado en los datos del cua- 
dro 1: la mayoría de ellos son solteros (el 70 por 100), pero también se encuentran ampliamente representados en este grupo los divorciados y separados (el 22 por 100 de los desempleados que viven en entornos no familiares); predominan los varones (60 por 100, frente al 40 por 100 que son mujeres) y, como ya se señaló más arriba, el único grupo de edad sobrerrepresentado es el de los desempleados de más de 45 años (casi el 40 por 100 de estos «solitarios»).

\section{CUADRO 1}

Perfil sociodemográfico de los desempleados que viven en entornos no familiares

\begin{tabular}{|c|c|}
\hline & Porcentaje \\
\hline \multicolumn{2}{|l|}{ Edad } \\
\hline 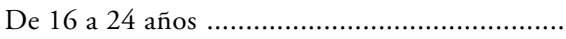 & 12 \\
\hline De 25 а 34 años & 31 \\
\hline De 35 a 44 años & 18 \\
\hline De 45 y más años ................ & 39 \\
\hline TOTAL . & 100 \\
\hline \multicolumn{2}{|l|}{ Género } \\
\hline Varones & 60 \\
\hline 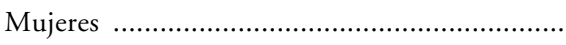 & 40 \\
\hline TOTAL ............ & 100 \\
\hline \multicolumn{2}{|l|}{ Estado civil } \\
\hline 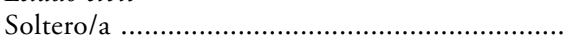 & 71 \\
\hline Casado/a & 2 \\
\hline Viudo/a & 5 \\
\hline Divorciado/a, separado/a ................................. & 22 \\
\hline ................... & 100 \\
\hline
\end{tabular}

Dejando de lado, por el momento, a los que viven en entornos no familiares, cabe mencionar, siquiera sea de forma somera, alguna de las características de los hogares en los que residen los desempleados. El tamaño medio de estas unidades familiares es de 3,9 personas, con un valor modal de 4 miembros; la dispersión es relativamente escasa, como pone de manifiesto el hecho de que casi tres de cada cuatro de esos hogares (el 73 por 100) están constituidos por entre tres y cinco miembros; en resumidas cuentas, se trata de una "familia tipo» que se ajusta perfectamente al modelo dominante de familia nuclear de tamaño bastante reducido. 
En casi dos tercios (el 63 por 100) de los hogares en que residen los desempleados inscritos en el INEM hay alguna persona ocupada, sea en un trabajo regular, a jornada completa (la gran mayoría), sea en uno esporádico o a tiempo parcial (en una minoría de casos). Los datos son los que muestra el cuadro 2 , donde se aprecia que en una proporción relativamente importante de hogares (el 14 por 100) trabajan incluso dos o más personas.

\section{CUADRO 2}

\section{Personas que trabajan en los hogares de los desempleados}

(Base: desempleados que viven en un entorno familiar)

\begin{tabular}{|c|c|}
\hline & $\begin{array}{l}\text { Porcentaje } \\
\text { de hogares }\end{array}$ \\
\hline No hay ninguna persona que trabaje ................. & 36,7 \\
\hline 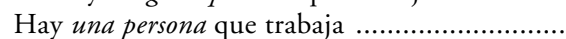 & 48,8 \\
\hline 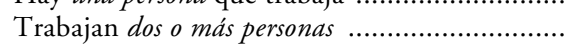 & 14,5 \\
\hline
\end{tabular}

\section{LA PROTECCIÓN SOCIAL AL DESEMPLEO}

Algo más de un tercio de los desempleados inscritos en el INEM entrevistados en esta encuesta (el 35 por 100) declaraba percibir algún tipo de emolumento que venía a cubrir su situación de desempleo. Esta protección que se ofrece por parte de los poderes públicos puede ser de dos tipos: de una parte, está la prestación contributiva, que "tiene como objeto proporcionar unos ingresos sustitutivos de las rentas dejadas de percibir como consecuencia de la pérdida de un empleo o de la reducción de la jornada de trabajo», y, de otra, el subsidio asistencial, que "garantiza un mínimo de protección en determinadas circunstancias a los trabajadores desempleados que no cumplen los requisitos para recibir la prestación contributiva o la han agotado ${ }^{2}$. De los desempleados entrevistados, el 19 por 100 percibía la prestación contributiva en el momento de realizarse la encuesta, y el 16 por 100 el subsidio asistencial.

Si hay algo que ponen rotundamente de manifiesto los datos que se recogen en el cuadro 3 es la importante desigualdad en la cobertura social que se ofrece a los desempleados, según sean su edad y género:

2 Así se definen ambos mecanismos de protección en los folletos divulgativos editados por el Instituto Nacional de Empleo para información de los desempleados. 
- Según la edad, los 45 años marcan una frontera muy significativa en cuanto al grado de protección, especialmente en lo que se refiere a la protección asistencial (no contributiva). En cualquier caso, el porcentaje de desempleados protegidos se eleva hasta el 56 por 100 entre los mayores de 45 años, siendo notablemente más bajo entre los desempleados más jóvenes: el 34 por 100 de los que tienen entre 35 y 44 años; el 32 por 100 de los de 25 a 44 años, y apenas un 13 por 100 de los menores de 25 años.

- Según el género, los varones se encuentran mucho más protegidos que las mujeres ante la situación de desempleo: de hecho, el porcentaje de varones que percibe algún tipo de cobertura (48 por 100) duplica el de las mujeres $(24$ por 100$)$, siendo la diferencia aún más llamativa en el caso de la prestación contributiva, que perciben un 27 por 100 de los varones desempleados y sólo un 12 por 100 de las mujeres.

\section{CUADRO 3}

\section{Cobertura social al desempleo}

\begin{tabular}{|c|c|c|c|c|c|}
\hline & $\begin{array}{c}\text { Cobra } \\
\text { prestación } \\
\text { contributiva }\end{array}$ & $\begin{array}{c}\text { Cobra } \\
\text { subsidio } \\
\text { asistencial }\end{array}$ & $\begin{array}{c}\text { No } \\
\text { recibe } \\
\text { protección }\end{array}$ & Total & $(N)$ \\
\hline 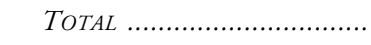 & 19 & 16 & 65 & 100 & $(4.658)$ \\
\hline \multicolumn{6}{|l|}{ Género } \\
\hline .......................... & 27 & 21 & 52 & 100 & $(2.102)$ \\
\hline 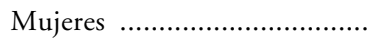 & 12 & 12 & 76 & 100 & $(2.555)$ \\
\hline \multicolumn{6}{|l|}{ Edad } \\
\hline 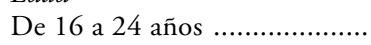 & 9 & 4 & 87 & 100 & (922) \\
\hline 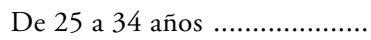 & 19 & 13 & 68 & 100 & $(1.519)$ \\
\hline 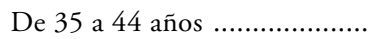 & 19 & 15 & 66 & 100 & (1.019) \\
\hline 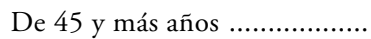 & 27 & 29 & 44 & 100 & $(1.190)$ \\
\hline
\end{tabular}

La explicación de estas diferencias entre el nivel de cobertura social que reciben los adultos y los jóvenes y, sobre todo, los varones y las mujeres desempleados tiene que ver, sin duda, con la posición dominante de los varones adultos en el segmento más estable y protegido del mercado de trabajo, lo que provoca que, al ocupar posiciones laborales más sólidas y acumular más experiencia (han cotizado más y durante más tiempo), se encuentren más protegidos ante la contingencia del desempleo. Por esto mismo, aun cuando sufran esta circunstancia de quedar sin trabajo, pueden seguir desempeñando en mayor medida que las mujeres o que los jóvenes el papel de proveedores de los recursos necesarios para la unidad familiar. En este sentido, el sistema de pro- 
tección social por desempleo puede contemplarse como un reflejo más de la privilegiada posición de los varones adultos en el mercado de trabajo.

Las mujeres no sólo están protegidas en menor proporción que los varones, sino que las que lo están, lo están en menor medida, es decir, reciben unas prestaciones más reducidas. Según datos del año 1995, y referidos sólo a las contributivas, el importe de las que percibían las mujeres era significativamente inferior a las prestaciones que recibían los varones (2.569 pesetas brutas diarias, frente a 3.155) y, además, las recibían durante menos tiempo: 15,3 meses en promedio, frente a 17,2 meses de los varones (Valiente, 1998: 61). Estos datos coinciden bastante aproximadamente con los que resultan de la encuesta que se viene analizando, que ofrece unos promedios de 17,4 meses en la cobertura ofrecida a los varones y 16,5 en la de las mujeres, y unos importes medios de las prestaciones de 93.000 pesetas mensuales en el caso de los varones y 80.000 en el de las mujeres.

\section{TIPOLOGÍA DE LOS PARADOS}

Para analizar el rol que desempeñan los desempleados en el seno de la unidad familiar se ha construido una tipología que los clasifica según reciban o no algún tipo de cobertura por parte del INEM y según haya o no alguna persona ocupada en el seno del hogar en el que conviven. Si según la protección social que reciben los desempleados se distribuyen entre algo menos de un 35 por 100 que recibe algún tipo de cobertura — sea una prestación contributiva o un subsidio de desempleo-y casi otros dos tercios (65 por 100) que no reciben ningún tipo de ayuda, según la existencia o no de personas ocupadas en el seno de la unidad familiar se dividen entre un 61 por 100 de desempleados que conviven con alguna persona que trabaja y un 39 por 100 que reside en hogares en los que no hay nadie que tenga una ocupación.

El resultado de cruzar estas dos dimensiones es una tipología que da lugar a cuatro perfiles diferentes de desempleados:

- Desempleados proveedores o sostenedores de la unidad familiar, que son aquellos que perciben algún tipo de ayuda procedente del mecanismo formal de protección conocido como Estado del Bienestar y que conviven en un hogar en donde no hay ninguna otra persona que tenga una ocupación, lo que significa que, a pesar de la situación de desempleo en que se encuentra, el individuo de referencia tiene que seguir desempeñando la tarea de proveer de los recursos necesarios a la familia. Este tipo de desempleados representan el 17 por 100 de los que estaban inscritos en el INEM en el momento de realizarse la encuesta.

- Coproveedores del hogar familiar son los desempleados que se encuentran cubiertos en alguna medida por el sistema formal de protección al desempleo y conviven en un hogar en el que existe algún otro miembro que tra- 
baja. Son casi el 18 por 100 del total los desempleados que asumen esta función coproveedora —o proveedora subsidiaria— de la unidad familiar.

- Casi uno de cada cuatro desempleados (el 22 por 100) no recibe cobertura social alguna por parte del sistema formal de protección ni convive con ninguna persona ocupada; se trata de un colectivo que cabe considerar en situación de desamparo, ya que se encuentra al margen tanto del mecanismo de protección que ofrece el Estado del Bienestar, a través del INEM, como del más primario mecanismo de protección que representa la institución familiar.

- Por último, el colectivo más numeroso es el que representan los desempleados dependientes (43 por 100), es decir, aquellos que no reciben ninguna protección formal por su situación de desempleo pero que conviven en un hogar en el que hay otra persona que trabaja y que, por consiguiente, asume el papel de proveedor de recursos para la unidad familiar, mientras que el individuo desempleado queda en una situación de dependencia económica respecto a ese sustentador principal. Se trata de un grupo al que el Estado del Bienestar, fiel a su condición de mecanismo subsidiario de protección, deja fuera de su cobertura, en el bien entendido de que es la familia la que asume la función protectora de estos miembros en situación de precariedad.

\section{CUADRO 4}

Tipología de los desempleados

\begin{tabular}{cccc}
\hline & $\begin{array}{c}\text { No hay ninguna } \\
\text { persona ocupada } \\
\text { en el hogar }\end{array}$ & $\begin{array}{c}\text { Hay alguna } \\
\text { persona ocupada } \\
\text { en el hogar }\end{array}$ & Total \\
\cline { 2 - 4 } Recibe protección por desempleo …....... & $\begin{array}{c}\text { Proveedor } \\
(17 \text { por 100) }\end{array}$ & $\begin{array}{c}\text { Coproveedor } \\
(17,6 \text { por 100) }\end{array}$ & 34,6 \\
No recibe protección por desempleo $\ldots . .$. & $\begin{array}{c}\text { Desamparado } \\
(22,4 \text { por } 100)\end{array}$ & $\begin{array}{c}\text { Dependiente } \\
(43 \text { por 100) }\end{array}$ & 65,4 \\
\cline { 2 - 4 } & 39,4 & 60,6 & 100,0 \\
\hline
\end{tabular}

En una primera aproximación a los rasgos sociodemográficos que se encuentran asociados a los distintos tipos de desempleados, y antes de entrar en un análisis más detallado, al que se procederá más adelante, cabe destacar las importantes diferencias que se observan según el género, la edad y el estado civil:

- Según el género, los desempleados varones tienden a desempeñar en bastante mayor medida que las mujeres el rol de proveedores de recursos para 
la unidad familiar (lo son el 28 por 100 de ellos, contra el 8 por 100 de ellas), mientras que una buena mayoría de las mujeres desempleadas (el 56 por 100) son dependientes, es decir, no reciben cobertura social alguna y conviven en hogares donde hay otra persona que trabaja y que aporta los recursos económicos necesarios.

- Según la edad, entre los desempleados más jóvenes (aquellos que tienen de 16 a 24 años) predomina de manera muy clara el tipo dependiente, hasta el punto de que casi dos de cada tres entrevistados (el 65 por 100) quedan catalogados dentro de él, mientras que entre los desempleados de mayor edad (45 años o más) se dan más frecuentemente los roles de proveedor (30 por 100) o coproveedor (26 por 100) de la unidad familiar.

- El estado civil de los desempleados también muestra cierta asociación con el rol desempeñado dentro de la unidad familiar, de modo que los desempleados solteros son, en buena medida, dependientes, mientras que entre los viudos y divorciados o separados predominan el rol de proveedor o la situación de desamparo causada por la ausencia de recursos, y los casados son, sobre todo, proveedores o coproveedores de recursos.

\section{CUADRO 5}

Perfil sociodemográfico de los distintos tipos de desempleados

\begin{tabular}{|c|c|c|c|c|c|c|}
\hline & Proveedor & Coproveedor & Desamparado & Dependiente & Total & $(N)$ \\
\hline TOTAL ….......................... & 17 & 18 & 22 & 43 & 100 & $(4.658)$ \\
\hline \multicolumn{7}{|l|}{ Género } \\
\hline 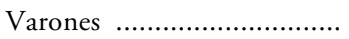 & 28 & 20 & 25 & 27 & 100 & $(2.102)$ \\
\hline 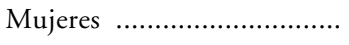 & 8 & 16 & 20 & 56 & 100 & $(2.555)$ \\
\hline \multicolumn{7}{|l|}{ Edad } \\
\hline De 16 a 24 años ...................... & 4 & 9 & 22 & 65 & 100 & $(922)$ \\
\hline De 25 a 34 años .................. & 14 & 18 & 24 & 44 & 100 & $(1.516)$ \\
\hline De 35 a 44 años ................... & 19 & 15 & 24 & 42 & 100 & $(1.019)$ \\
\hline De 45 y más años ................. & 30 & 26 & 19 & 25 & 100 & $(1.187)$ \\
\hline \multicolumn{7}{|l|}{ Estado civil } \\
\hline 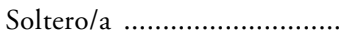 & 10 & 9 & 31 & 50 & 100 & $(1.858)$ \\
\hline Casado/a ................................ & 21 & 25 & 14 & 40 & 100 & $(2.508)$ \\
\hline 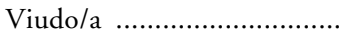 & 29 & 22 & 39 & 9 & 100 & $(54)$ \\
\hline Divorciado/a o separado/a .. & 31 & 12 & 39 & 18 & 100 & $(237)$ \\
\hline \multicolumn{7}{|l|}{ Nivel de estudios } \\
\hline Primarios o menos …............. & 26 & 20 & 25 & 29 & 100 & $(1.376)$ \\
\hline EGB & 15 & 17 & 22 & 46 & 100 & $(1.460)$ \\
\hline FP & 11 & 16 & 19 & 54 & 100 & $(760)$ \\
\hline Bachillerato ............................. & 14 & 20 & 18 & 48 & 100 & $(518)$ \\
\hline Universitarios .......................... & 10 & 14 & 25 & 51 & 100 & $(495)$ \\
\hline
\end{tabular}


Al margen de la asociación que muestra la posesión de determinadas características sociodemográficas por parte de los desempleados con su inclusión en uno u otro tipo, tiene especial interés el conocimiento de las interacciones que se producen entre estas variables. Por ello, más allá de esta somera descripción de algunos rasgos asociados a estos tipos de desempleados, procede un análisis más detallado tanto de las características que los conforman como de las circunstancias que confluyen en los hogares de los que forman parte cada uno de ellos.

\section{LOS RASGOS CARACTERÍSTICOS DE LOS DESEMPLEADOS PROVEEDORES Y DE SUS HOGARES}

Como ya se ha señalado anteriormente, el 17 por 100 de los desempleados inscritos en el INEM como demandantes de empleo asumen, a pesar de su situación de desempleo, la función de proveedores principales de los recursos económicos de su unidad familiar, ya que no hay ninguna otra persona que conviva en el hogar y que disponga de un trabajo. Para caracterizar mejor a este colectivo se ha procedido a realizar un análisis de segmentación, cuyos resultados se exponen en el cuadro 6, y de los que cabe concluir que las variables fundamentales que definen a los desempleados que desempeñan el rol de proveedores son el género y el estado civil. En efecto, entre los varones no solteros (sean casados, viudos, divorciados o separados), que representan algo más de la cuarta parte de los desempleados inscritos en el INEM, el porcentaje de los que asumen la función de proveedores principales de los recursos necesarios para la unidad familiar se eleva hasta el 39 por 100, muy por encima del 17 por 100 que se registraba en el conjunto de la población desempleada.

Aunque claramente por detrás de este segmento, también asumen funciones proveedoras en mayor medida que el conjunto de los desempleados los varones solteros de más de 45 años (el 36 por 100 de ellos, aun cuando se trata de un colectivo muy reducido), las mujeres solteras de más de 35 años y las que están separadas, divorciadas o viudas, cualquiera que sea su edad: algo más de una de cada cuatro desempleadas en las que concurren estas características es la principal o única proveedora de recursos materiales en su hogar.

En el extremo opuesto, como los colectivos de desempleados que en menor medida desempeñan el papel de proveedores de la unidad familiar se encuentran principalmente las mujeres casadas, que representan algo más del 30 por $100 \mathrm{de}$ los desempleados, pero sólo el 6 por 100 de las cuales asume la función de ser la principal proveedora del hogar, muy lejos del porcentaje que se registraba entre los varones en sus mismas circunstancias. Los desempleados solteros, por otra parte, con diferencias según el género y, sobre todo, la edad, también se caracterizan por desempeñar raramente ese papel de proveedores de los recursos económicos del hogar familiar: lo hacen sólo el 14 por 100 de los solteros varones de 25 a 44 años, el 8 por 100 de las mujeres solteras de 25 a 34 años y 
porcentajes aún más bajos entre los solteros más jóvenes: el 4 por 100 de los varones de 16 a 24 años y el 3 por 100 de las mujeres solteras de esas mismas edades.

\section{CUADRO 6}

Análisis de segmentación de los desempleados proveedores

\begin{tabular}{|c|c|c|c|}
\hline Caracteristicas del segmento & $(N)$ & $\begin{array}{c}\% \text { que representa el } \\
\text { segmento sobre la } \\
\text { población desempleada }\end{array}$ & $\begin{array}{c}\% \text { de desempleados } \\
\text { proveedores } \\
\text { en el segmento }\end{array}$ \\
\hline Varones no solteros & $(1.197)$ & 25,7 & 39,3 \\
\hline Varones solteros de 45 años y más ........ & $(80)$ & 1,7 & 35,9 \\
\hline Mujeres solteras de 35 años y más ........ & $(140)$ & 3,0 & 26,0 \\
\hline Mujeres separadas, divorciadas o viudas .... & $(183)$ & 3,9 & 25,6 \\
\hline Varones solteros de 25 a 44 años ............ & $(471)$ & 10,1 & 13,9 \\
\hline Mujeres solteras de 25 a 34 años ........... & (343) & 7,4 & 8,0 \\
\hline 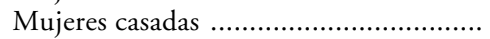 & $(1.420)$ & 30,5 & 6,0 \\
\hline Varones solteros de 16 a 24 años ............ & $(354)$ & 7,6 & 3,6 \\
\hline Mujeres solteras de 16 a 24 años ........... & $(470)$ & 10,1 & 3,2 \\
\hline
\end{tabular}

Todos estos datos que se ofrecen en el cuadro 6 vienen a convalidar una imagen que se corresponde fielmente con el estereotipo más tradicional de la división de roles en el hogar, de modo que al varón casado, como consecuencia de su estatus de "cabeza de familia», le corresponde asumir el papel de proveedor de los recursos necesarios para la unidad familiar, incluso cuando queda en la situación de desempleo. Lo contrario ocurre entre las mujeres: cuando están casadas apenas desempeñan el rol de proveedoras principales del hogar, cosa que sí hacen cuando no hay un varón que asuma ese papel, como es en el caso de las separadas, divorciadas o viudas y en el de las mujeres solteras de más de 35 años de edad.

Como ha quedado repetidamente de manifiesto, la definición de proveedores implica que los desempleados que desempeñan este rol conviven en un entorno familiar en el que no hay ninguna otra persona ocupada, sea de manera fija o temporal, a tiempo parcial o con jornada completa. Sin embargo, ello no significa necesariamente que los únicos recursos económicos de que disponen esos hogares sean los ingresos procedentes de las prestaciones o subsidios que percibe el individuo en situación de desempleo, ya que un porcentaje muy significativo (el 52 por 100) declara que dispone de alguna otra fuente de ingresos.

De hecho, aunque en la mayoría de los casos (el 76 por 100) el desempleado proveedor es la persona que aporta la mayor cantidad de ingresos (cuadro 
7), no faltan los hogares en los que es otra o son otras las personas que asumen ese rol de proveedores principales, ocupando el individuo desempleado un lugar secundario en la provisión de recursos para la unidad familiar. Esto ocurre en algo más de una quinta parte de los casos (el 21 por 100), y las personas que, en estas circunstancias, adquieren la posición de sustentador principal son los cónyuges (o parejas) o los progenitores del individuo desempleado.

\section{CUADRO 7}

Posición del desempleado proveedor en el seno de la unidad familiar

\begin{tabular}{|c|c|c|c|}
\hline & $\begin{array}{l}\text { Cobra prestación } \\
\text { por desempleo }\end{array}$ & $\begin{array}{l}\text { Cobra subsidio } \\
\text { asistencial }\end{array}$ & Total \\
\hline Es la persona que aporta más ingresos al hogar ... & 80 & 73 & 76 \\
\hline Aporta lo mismo que otra $\mathrm{u}$ otras personas ....... & 1 & 3 & 2 \\
\hline Hay otra persona que aporta más ........................... & 19 & 24 & 21 \\
\hline NC & - & - & 1 \\
\hline TOTAL & $\begin{array}{c}100 \\
(355)\end{array}$ & $\begin{array}{c}100 \\
(354)\end{array}$ & $\begin{array}{c}100 \\
(710)\end{array}$ \\
\hline \multicolumn{4}{|l|}{$\begin{array}{l}\text { Relación familiar del desempleado con la persona } \\
\text { que más ingresos aporta }\end{array}$} \\
\hline 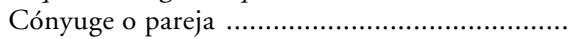 & 22 & 55 & 40 \\
\hline 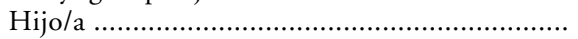 & 65 & 26 & 43 \\
\hline 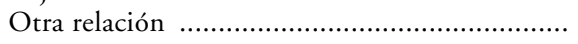 & 13 & 19 & 17 \\
\hline $\begin{array}{l}\text { TOTAL } \\
\text { (N) }\end{array}$ & $\begin{array}{l}100 \\
(67)\end{array}$ & $\begin{array}{l}100 \\
(85)\end{array}$ & $\begin{array}{c}100 \\
(152)\end{array}$ \\
\hline
\end{tabular}

Entre las fuentes complementarias de ingresos que contribuyen al mantenimiento de la unidad familiar se sitúan, en primer lugar, las pensiones, sean de jubilación, viudedad, invalidez o cualquier otra, que percibe algún miembro de la familia: en más de uno de cada cuatro hogares (el 28 por 100) de desempleados proveedores se perciben ingresos procedentes de este origen. En segundo lugar hay que mencionar las prestaciones o subsidios por desempleo que recibe otra persona distinta al entrevistado, lo que ocurre en uno de cada diez de estos hogares. Por último, las ayudas procedentes de instituciones públicas o privadas (3 por 100) o de relaciones personales, de amigos o familiares (9 por 100), así como el recurso a ingresos procedentes de «trabajos ocasionales» ${ }^{3}$, que confiesa

3 El carácter de estos «trabajos ocasionales» no queda claro en la encuesta, pues si bien puede ocurrir que el individuo desempleado los realice de forma plenamente legal, dándose de baja de su inscripción en el INEM cada vez que le surge uno de ellos, también es posible que al menos 
el 8 por 100 de los desempleados proveedores, son los orígenes de otros recursos económicos que vienen a complementar los disponibles en estos hogares.

Según el tipo de protección social que se les ofrece, los desempleados que se ven obligados a desempeñar el papel de proveedores de recursos para el hogar se dividen en dos mitades prácticamente iguales entre quienes perciben una prestación contributiva por su situación de desempleo (51 por 100) y quienes reciben únicamente un subsidio asistencial equivalente al 75 por 100 del salario mínimo interprofesional (el 49 por 100). Como es fácil prever, la situación de unos y otros difiere sustancialmente en cuanto a los recursos disponibles, ya que mientras el importe medio de la prestación contributiva ascendía a algo más de 90.000 pesetas mensuales, el subsidio asistencial se situaba por debajo de las 50.000 pesetas $^{4}$; en consecuencia, son los hogares de estos últimos los que en mayor medida se ven obligados a disponer de ayudas económicas y a recurrir a la economía "oculta» para conseguir los recursos suplementarios que necesitan. Como se pone de relieve en el cuadro 8, las fuentes complementarias de ingresos se encuentran más diversificadas en los hogares en los que el proveedor percibe únicamente un subsidio asistencial: en el 58 por 100 de ellos existen además otros ingresos, cosa que sólo ocurre en el 47 por 100 de los hogares en los que el proveedor desempleado percibe una prestación contributiva por desempleo.

Las diferencias son más importantes, precisamente, en la disponibilidad de aquellos recursos que indican una mayor precariedad, tales como las ayudas de familiares o amigos, que reciben un 16 por 100 de los hogares en los que el desempleado proveedor cobra un subsidio asistencial y sólo un 3 por 100 de los hogares en los que el proveedor tiene derecho a percibir una prestación contributiva; de igual modo, reconocen obtener ingresos por trabajos ocasionales el 11 por 100 de los desempleados proveedores que cobran subsidio y sólo el 5 por 100 de los que perciben prestación.

De manera coherente con todo lo manifestado hasta aquí, se observa la existencia de un sentimiento mucho más acusado de precariedad entre los desempleados proveedores que perciben el subsidio asistencial que entre los que perciben la prestación contributiva. De hecho, al enjuiciar la cobertura social que reciben por su situación de desempleo, apenas la mitad (el 47 por 100) de los proveedores que reciben la prestación contributiva por desempleo tildan de insuficiente para vivir la cantidad de dinero que reciben en tal concepto, mientras que el porcentaje se eleva hasta el 84 por 100 en el caso de los desempleados que perciben el subsidio asistencial. Los datos del cuadro 9 ponen de relieve la magnitud de las diferencias.

una parte de los casos se puedan incluir de lleno en lo que se conoce como «economía sumergida», conllevando, incluso, una condición fraudulenta, pues no conviene olvidar que se trata de personas que reciben protección social por su situación de desempleo.

${ }^{4}$ En 1996, año en el que se realiza la encuesta y, por consiguiente, al que se refieren todos los datos, el importe de este subsidio asistencial era de 48.690 pesetas para los trabajadores mayores de 18 años y de 37.665 para los que tenían entre 16 y 18 años. 


\section{CUADRO 8}

Ingresos complementarios en los hogares de los desempleados proveedores (Porcentaje de hogares que dispone de alguno de los siguientes ingresos)

\begin{tabular}{|c|c|c|c|}
\hline & Total & $\begin{array}{l}\text { Proveedores } \\
\text { que perciben } \\
\text { prestación } \\
\text { contributiva }\end{array}$ & $\begin{array}{l}\text { Proveedores } \\
\text { que cobran } \\
\text { subsidio } \\
\text { asistencial }\end{array}$ \\
\hline $\begin{array}{l}\text { Pensiones de algún miembro de la familia ...... } \\
\text { Prestación o subsidio de desempleo de algún } \\
\text { otro miembro de la familia distinto al entre- } \\
\text { vistado }\end{array}$ & 28 & 32 & 24 \\
\hline $\begin{array}{l}\text { Becas o ayudas al estudio de algún miembro } \\
\text { de la unidad familiar ............................ } \\
\text { Ayudas de Instituciones Públicas o Privadas .. } \\
\text { Ayudas de familiares o amigos ...................... } \\
\text { Ingresos procedentes de trabajos ocasionales } \\
\text { realizados por el entrevistado ........................ }\end{array}$ & $\begin{array}{l}5 \\
3 \\
9\end{array}$ & $\begin{array}{l}3 \\
2 \\
3\end{array}$ & $\begin{array}{r}7 \\
4 \\
16\end{array}$ \\
\hline 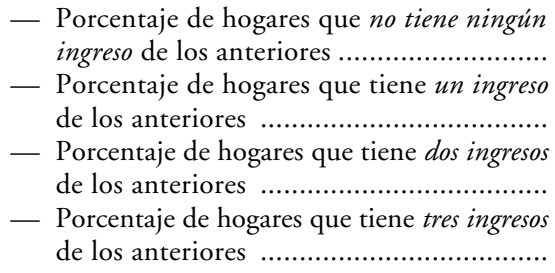 & 42 & 41 & $\begin{array}{l}42 \\
44 \\
12\end{array}$ \\
\hline $\begin{array}{l}\text { TOTAL } \\
\text { (N) }\end{array}$ & $\begin{array}{l}100 \\
(789)\end{array}$ & $\begin{array}{c}100 \\
(399)\end{array}$ & $\begin{array}{c}100 \\
(390)\end{array}$ \\
\hline
\end{tabular}

\section{CUADRO 9}

Valoración de la protección por desempleo por parte de los desempleados proveedores

\begin{tabular}{|c|c|c|}
\hline $\begin{array}{c}\text { En sus actuales circunstancias personales } \\
\text { y familiares, el dinero que recibe le resulta... }\end{array}$ & $\begin{array}{l}\text { Cobra prestación } \\
\text { por desempleo }\end{array}$ & $\begin{array}{l}\text { Cobra subsidio } \\
\text { asistencial }\end{array}$ \\
\hline Suficiente para vivir & 16 & 4 \\
\hline Muy justo & 36 & 12 \\
\hline Claramente insuficiente & 47 & 84 \\
\hline NC & 1 & - \\
\hline $\begin{array}{l}\text { TOTAL } \\
\text { (N) }\end{array}$ & $\begin{array}{c}100 \\
(397)\end{array}$ & $\begin{array}{c}100 \\
(390)\end{array}$ \\
\hline
\end{tabular}


Dentro de este tipo de hogares que se viene analizando, caracterizado fundamentalmente por la ausencia de persona alguna que trabaje para aportar los recursos necesarios para la unidad familiar y, en consecuencia, por el hecho de que una persona en situación de desempleo se ve obligada a asumir el rol de suministrador de esos recursos, hay diferencias muy apreciables, que se dan en función de dos circunstancias principales:

- el tipo de cobertura por desempleo que se recibe, según proceda ésta de una prestación contributiva o de un subsidio asistencial, y

- la existencia o no de otros ingresos en el hogar, aunque sean precarios, que vengan a complementar las rentas aportadas por el individuo desempleado.

La primera y más relevante diferencia salta a la vista al considerar la distribución de los ingresos mensuales que, por todos los conceptos, entran en estos hogares. Tomando como única referencia el valor modal de esa distribución se observa que en las unidades familiares en las que el individuo desempleado percibe una prestación contributiva y, además, hay alguna otra aportación de recursos, el intervalo modal de ingresos se sitúa entre 100.001 y 150.000 pesetas, lo que viene a coincidir con el intervalo modal que resulta en las encuestas realizadas a la población en general.

El intervalo modal de ingresos de los hogares en los que el único recurso es la prestación contributiva que percibe el individuo desempleado se sitúa entre 50.001 y 100.000 pesetas $^{5}$, intervalo que coincide con el que se da en los hogares en los que los recursos proceden de un subsidio asistencial completado con otros ingresos. Sin embargo, en este segundo caso cabe inferir una situación de mayor precariedad a causa de que el tamaño del hogar es significativamente más grande: la moda señala una cifra de cuatro individuos, frente a dos que constituían la moda del tipo anterior.

Por último, la situación más precaria corresponde, lógicamente, a los hogares en los que el único ingreso procede de un subsidio asistencial cuyo importe, salvo circunstancias excepcionales, es del 75 por 100 del salario mínimo interprofesional ${ }^{6}$ y se sitúa por debajo de las 50.000 pesetas mensuales, para un tamaño del hogar que tiene la moda en tres miembros.

5 Conviene recordar que el importe medio de esa prestación se situaba en 90.000 pesetas.

${ }^{6}$ Existe un subsidio especial para desempleados de más de 45 años que han agotado la prestación contributiva de 24 meses, carecen de otras rentas y tienen cargas familiares que, según el número de estas cargas, puede llegar al 100 o al 125 por 100 del salario mínimo interprofesional. 


\section{CUADRO 10}

Ingresos totales en los hogares de los desempleados proveedores

\begin{tabular}{|c|c|c|c|c|}
\hline Tipo de percepción & $\begin{array}{c}\text { Existencia o no } \\
\text { de ingresos alternativos }\end{array}$ & $\begin{array}{l}\text { Intervalo } \\
\text { modal } \\
\text { de ingresos }\end{array}$ & $\begin{array}{c}\text { Tamaño } \\
\text { modal } \\
\text { de los hogares }\end{array}$ & $(N)$ \\
\hline Prestación contributiva & $\begin{array}{l}\text { - Hay otros ingresos en el } \\
\text { hogar } \\
\text { - No hay ningún otro in- } \\
\text { greso en el hogar }\end{array}$ & $\begin{array}{l}100.001- \\
150.000 \text { pts. } \\
50.001- \\
100.000 \text { pts. }\end{array}$ & $\begin{array}{l}3 \\
2\end{array}$ & $\begin{array}{l}\text { (187) } \\
(209)\end{array}$ \\
\hline Subsidio asistencial & $\begin{array}{l}\text { - Hay otros ingresos en el } \\
\text { hogar } \\
\text { - No hay ningún otro in- } \\
\text { greso en el hogar }\end{array}$ & $\begin{array}{l}50.001- \\
100.000 \text { pts. } \\
\text { Hasta } \\
50.000 \text { pts. }\end{array}$ & $\begin{array}{l}4 \\
3\end{array}$ & $\begin{array}{l}(225) \\
(166)\end{array}$ \\
\hline
\end{tabular}

Los diferentes grados de precariedad que se advierten en los datos del cuadro 10 se ven confirmados al analizar la percepción subjetiva que tienen los individuos desempleados de la situación económica que atraviesa su unidad familiar, en comparación con lo que puede ser la situación típica de «la mayoría de las familias de este país». En efecto, los datos del cuadro 11 ponen de relieve que en aquellos hogares en los que, aunque no haya ninguna persona ocupada, los ingresos procedentes de una prestación por desempleo se ven completados con otros ingresos complementarios, las opiniones se encuentran divididas casi en dos mitades entre quienes ven su situación igual que la mayoría de las familias del país y quienes la ven peor; la percepción cambia en los demás tipos de hogares y va creciendo de manera muy significativa la sensación de precariedad, entendida como el sentimiento de estar peor que la mayoría de la gente, en los hogares en los que se recibe la prestación sin otros ingresos, en los que se percibe un subsidio complementado con otros recursos y, por último, en los que el único recurso es el subsidio.

Utilizando para medir esa percepción una escala de 0 a 10 puntos, en la que el 0 significa que el entrevistado considera que «su situación económica familiar es mucho peor que la de la mayoría de las familias de este pais" y el 10 significa, por el contrario, que «su situación económica familiar es mucho mejor que la de la mayoría de las familias de este país", se constata la existencia de grandes diferencias en la sensación de precariedad económica, que es notablemente más acusada en los hogares en los que el proveedor percibe el subsidio asistencial (con una puntuación media de 3,5 puntos) que en los hogares en los que el desempleado que asume el rol de proveedor percibe una prestación contributiva (cuyo índice de precariedad alcanza una puntuación de 4,1 puntos si no hay otros ingresos y de 4,4 si los hay). 


\section{CUADRO 11}

Percepción subjetiva de la situación económica de los hogares de los desempleados proveedores

(Situación económica de la familia en relación con la mayoría de las familias del país)

\begin{tabular}{|c|c|c|c|c|c|c|c|}
\hline Tipo de percepción & $\begin{array}{c}\text { Existencia o no } \\
\text { de ingresos alternativos }\end{array}$ & Peor & Igual & Mejor & $N C$ & Total & Media* \\
\hline \multirow[t]{2}{*}{ Prestación contributiva } & $\begin{array}{l}\text { - Hay otros ingresos en } \\
\text { el hogar }\end{array}$ & 44 & 42 & 9 & 5 & 100 & 4,4 \\
\hline & greso en el hogar & 54 & 34 & 10 & 2 & 100 & 4,1 \\
\hline \multirow[t]{2}{*}{ Subsidio asistencial } & $\begin{array}{l}\text { - Hay otros ingresos en } \\
\text { el hogar }\end{array}$ & 66 & 29 & 3 & 2 & 100 & 3,5 \\
\hline & $\begin{array}{l}\text { No nay ningun otro in- } \\
\text { greso en el hogar }\end{array}$ & 70 & 19 & 10 & 1 & 100 & 3,5 \\
\hline TOTAL & & 58 & 31 & 8 & 3 & 100 & 3,9 \\
\hline
\end{tabular}

* Puntuación media en una escala de 0 a 10 puntos en la que el 0 significa que el entrevistado considera que «su situación económica familiar es mucho peor que la de la mayoría de las familias de este país" y el 10 significa que "su situación económica familiar es mucho mejor que la de la mayoría de las familias de este país»; una puntuación de 5 habría que interpretarla, por consiguiente, como que el entrevistado opina que su situación económica familiar es equivalente a la de la mayoría de las familias del país.

\section{LOS DESEMPLEADOS COPROVEEDORES Y LOS HOGARES EN DONDE SE INSERTAN}

Como se recordará, casi el 18 por 100 de los desempleados eran incluidos en esta categoría, que abarcaba a aquellos que recibían una prestación o subsidio y que, al mismo tiempo, convivían en el seno de una familia en la cual había alguna otra persona que trabajaba, asumiendo, por consiguiente, el rol de proveedor principal del hogar; en este sentido, estos desempleados llamados coproveedores ocuparían una posición subsidiaria en la provisión de los recursos demandados en la unidad familiar.

La primera diferencia que salta a la vista al comparar el perfil de estos coproveedores con el de los desempleados que desempeñaban el rol de proveedores principales es de género: mientras que entre los desempleados proveedores predominaban abrumadoramente los varones ( 73 por 100 , frente a un 27 por 100 de mujeres), en el caso de los coproveedores existe un notable equilibrio: el 51 por 100 son varones y el 49 por 100 mujeres. Sin embargo, este equilibrio es sólo aparente, puesto que dentro de la misma categoría de coproveedores hay notables diferencias entre los papeles que desempeñan los varones y las muje- 
res. Como muestran los datos del cuadro 12, cuando una mujer desempleada recibe una prestación social por su situación de desempleo y hay otra persona ocupada en el hogar, en la práctica totalidad de los casos (92 por 100) esa otra persona aporta más recursos al hogar que la mujer desempleada; este porcentaje es sólo del 52 por 100 cuando el desempleado es un varón.

Por otra parte, cuando la mujer ocupa esa posición coproveedora subalterna, la persona que aporta más ingresos al hogar familiar es casi siempre su cónyuge o pareja (en el 79 por 100 de los casos). Por el contrario, cuando es el varón quien aporta menos ingresos, su cónyuge o pareja sólo es quien más aporta en el 46 por 100 de los casos; en el resto es otra la relación familiar que une al varón desempleado coproveedor con el sustentador principal.

\section{CUADRO 12}

Posición del desempleado coproveedor en el seno de la unidad familiar, según el género

\begin{tabular}{|c|c|c|c|}
\hline & Varones & Mujeres & Total \\
\hline Es la persona que aporta más ingresos al hogar.. & 44 & 7 & 26 \\
\hline Aporta lo mismo que otra u otras personas ....... & 4 & 1 & 3 \\
\hline Hay otra persona que aporta más .......................... & 52 & 92 & 71 \\
\hline NC & - & - & - \\
\hline TOTAL & $\begin{array}{c}100 \\
(419)\end{array}$ & $\begin{array}{c}100 \\
(397)\end{array}$ & $\begin{array}{l}100 \\
(816)\end{array}$ \\
\hline
\end{tabular}

\begin{tabular}{|c|c|c|c|}
\hline \multicolumn{4}{|l|}{$\begin{array}{l}\text { Relación familiar del desempleado con la persona } \\
\text { que más ingresos aporta }\end{array}$} \\
\hline 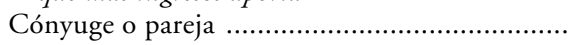 & 46 & 79 & 67 \\
\hline 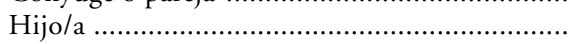 & 31 & 16 & 22 \\
\hline Otra relación & 23 & 5 & 11 \\
\hline TOTAL & $\begin{array}{c}100 \\
(219)\end{array}$ & $\begin{array}{c}100 \\
(363)\end{array}$ & $\begin{array}{c}100 \\
(581)\end{array}$ \\
\hline
\end{tabular}

En general, los hogares en los que hay alguna persona que trabaja y, además, existe una persona desempleada que percibe algún tipo de protección social (coproveedora) no se caracterizan por vivir una situación de precariedad económica. La distribución de ingresos que confiesan muestra un intervalo modal que se sitúa entre 100.001 y 150.000 pesetas, pero en el 41 por 100 de los casos se reconocen unos ingresos de más de 150.000 pesetas mensuales.

Hay una diferencia, no obstante, que interesa destacar: en los hogares en los que el desempleado coproveedor es quien aporta más ingresos a la unidad familiar (coproveedor principal) existe una cierta sensación de precariedad que se traduce en la idea de que la situación económica familiar es peor que la habi- 
tual entre las familias de este país, cosa que no ocurre cuando el desempleado no es quien aporta más ingresos (se limita al papel de coproveedor subalterno), sino que esta función corresponde a una persona ocupada (cuadro 13).

Entre las familias de estos coproveedores subalternos existe una convicción bastante generalizada de que su situación económica familiar es igual a la de la mayoría de las familias del país. Así opina el 44 por 100 de los entrevistados y, en una escala de 0 a 10 puntos, consideran que la situación económica de sus familias respectivas merece una calificación de 4,7 puntos en promedio, muy próxima al 5,0 que se supone la media de las familias españolas. Entre los coproveedores principales, en cambio, existe una mayor sensación de precariedad: el 51 por 100 de ellos piensa que la situación de su familia es peor que la de la mayoría de las familias del país y, en una escala de 0 a 10 , conceden a la situación económica de su hogar una puntuación de 4,1.

\section{CUADRO 13}

Percepción subjetiva de la situación económica familiar en los hogares de los desempleados coproveedores

\begin{tabular}{|c|c|c|c|}
\hline $\begin{array}{l}\text { Situación económica de la familia } \\
\text { en relación con la situación } \\
\text { de la mayoría de las familias del país }\end{array}$ & $\begin{array}{c}\text { Coproveedor } \\
\text { principal }\end{array}$ & $\begin{array}{l}\text { Coproveedor } \\
\text { subalterno }\end{array}$ & Total \\
\hline Peor & 51 & 35 & 39 \\
\hline Igual & 38 & 44 & 42 \\
\hline 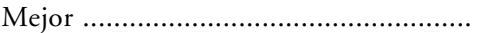 & 8 & 19 & 17 \\
\hline NC & 3 & 2 & 2 \\
\hline 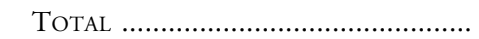 & 100 & 100 & 100 \\
\hline 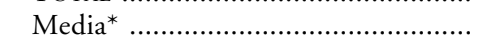 & 4,1 & 4,7 & 4,5 \\
\hline$(\mathrm{N})$ & (214) & $(581)$ & $(817)$ \\
\hline
\end{tabular}

* Ver nota bajo el cuadro 11 .

\section{LOS DESEMPLEADOS DEPENDIENTES}

Los desempleados que no reciben cobertura social alguna por parte del Estado del Bienestar y viven en un entorno familiar en el que hay alguna persona que está ocupada, sobre la que recae, por consiguiente, la responsabilidad de proveer de los recursos necesarios a la unidad familiar, son los que se catalogan como desempleados dependientes; son el colectivo más numeroso dentro de los desempleados inscritos en el INEM (el 43 por 100) y está constituido mayoritariamente por mujeres (el 71 por 100, frente al 29 por 100 que son varones) y por jóvenes (el 64 por 100 tiene menos de 35 años).

Un análisis de segmentación, cuyos resultados se muestran en el cuadro 14, permite precisar más las características de los desempleados que constituyen 
este grupo, en el cual se destacan dos segmentos particulares: los varones jóvenes (de 16 a 24 años) con estudios medios o superiores, entre los cuales el 64 por 100 de los desempleados son dependientes, y las mujeres de 16 a 34 años que viven en un entorno familiar, colectivo que representa prácticamente la mitad de la población en situación de desempleo (el 49,6 por 100), y entre las que las desempleadas dependientes llegan al 60 por 100.

\section{CUADRO 14}

Análisis de segmentación de los desempleados dependientes

\begin{tabular}{|c|c|c|c|}
\hline Caracteristicas del segmento & $(N)$ & $\begin{array}{l}\text { Porcentaje } \\
\text { que representa } \\
\text { el segmento } \\
\text { sobre la } \\
\text { población }\end{array}$ & $\begin{array}{c}\text { Porcentaje de } \\
\text { desempleados } \\
\text { dependientes } \\
\text { en el } \\
\text { segmento }\end{array}$ \\
\hline $\begin{array}{l}\text { Varones de } 16 \text { a } 24 \text { años y estudios por encima de } \\
\text { primarios }\end{array}$ & $(322)$ & 6,9 & 63,6 \\
\hline $\begin{array}{l}\text { Mujeres de } 16 \text { a } 34 \text { años que viven en un entorno } \\
\text { familiar }\end{array}$ & $(2.309)$ & 49,6 & 59,9 \\
\hline Varones de 16 a 24 años con estudios primarios .... & $(51)$ & 1,1 & 39,0 \\
\hline 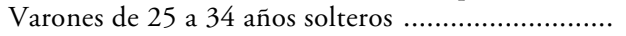 & $(354)$ & 7,6 & 38,4 \\
\hline Varones de 35 a 44 años con estudios universitarios.. & $(52)$ & 1,1 & 35,9 \\
\hline $\begin{array}{l}\text { Mujeres de } 35 \text { años y más que viven en un entorno } \\
\text { familiar }\end{array}$ & $(166)$ & 3,6 & 21,8 \\
\hline $\begin{array}{l}\text { Varones de } 35 \text { a } 44 \text { años con estudios no universita- } \\
\quad \text { rios }\end{array}$ & $(371)$ & 8,0 & 18,6 \\
\hline 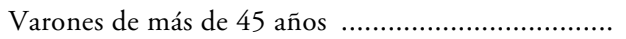 & $(722)$ & 15,5 & 13,6 \\
\hline Varones no solteros de 25 a 34 años ........................ & $(231)$ & 5,0 & 12,9 \\
\hline Mujeres que viven en un entorno no familiar ......... & $(81)$ & 1,7 & 0,0 \\
\hline
\end{tabular}

Una pregunta que resulta sumamente relevante a estos efectos es de quién dependen estos desempleados dependientes, o, lo que es lo mismo, quién es la persona que ejerce el papel de proveedor en los hogares en los que conviven estos desempleados. De las propias características que contribuyen a configurar este colectivo cabe intuir que hay dos tipos de desempleados dependientes y, consecuentemente, dos tipos de relaciones de dependencia familiar:

- De una parte están los desempleados más jóvenes ${ }^{7}$, hasta 25 años, sean varones o mujeres, que viven en una unidad familiar en la que el papel de proveedor de los recursos lo desempeñan los progenitores (normalmente el padre).

7 Para un análisis en profundidad de la dependencia económica de los jóvenes respecto de sus familias de origen, así como sobre el impacto del desempleo entre las jóvenes generaciones y sobre sus mecanismos de emancipación, se puede ver el estudio de Garrido y Requena (1996). 
- De otra parte están las mujeres casadas que dependen muy mayoritariamente de su cónyuge o pareja, que es quien aporta, en la gran mayoría de los casos, los recursos económicos necesarios para la supervivencia del hogar familiar.

Los datos que ofrece el cuadro 15 son sumamente reveladores: el 60 por 100 de los varones que se catalogan como desempleados dependientes lo son respecto de sus padres, y sólo uno de cada cuatro (el 26 por 100) depende de su cónyuge o pareja; en el caso de las mujeres, los porcentajes prácticamente se invierten, ya que el 60 por 100 de ellas vive en hogares en los que la principal aportación de recursos procede de su cónyuge o pareja, y solamente una de cada tres (el 34 por 100) lo hace en hogares donde los recursos los aporta el padre (o la madre, en una minoría de casos).

\section{CUADRO 15}

Relación familiar de los desempleados dependientes con el sustentador principal, según la edad y el género

\begin{tabular}{|c|c|c|c|c|c|}
\hline & $\begin{array}{l}\text { Cónyuge } \\
\text { o pareja }\end{array}$ & $\begin{array}{l}\text { Hijo } \\
\text { o hija }\end{array}$ & $\begin{array}{l}\text { Otra } \\
\text { relación }\end{array}$ & Total & $(N)$ \\
\hline TOTAL & 51 & 42 & 7 & 100 & (1.995) \\
\hline \multicolumn{6}{|l|}{ Género } \\
\hline 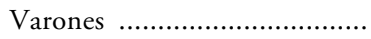 & 26 & 60 & 14 & 100 & $(576)$ \\
\hline 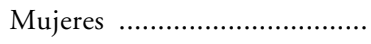 & 60 & 34 & 6 & 100 & $(1.418)$ \\
\hline \multicolumn{6}{|l|}{ Edad } \\
\hline 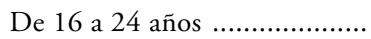 & 6 & 87 & 7 & 100 & $(600)$ \\
\hline 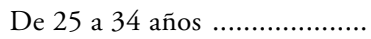 & 54 & 40 & 6 & 100 & $(668)$ \\
\hline 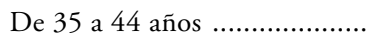 & 88 & 5 & 7 & 100 & $(428)$ \\
\hline 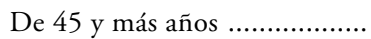 & 83 & 2 & 15 & 100 & (298) \\
\hline
\end{tabular}

Especialmente destacable, en este sentido, resulta el grupo de edad de 25 a 34 años. Si entre los desempleados más jóvenes (entre 16 y 24 años) predomina abrumadoramente la dependencia paterna y entre los de más edad, a partir de los 35, ésta es sustituida por la dependencia del cónyuge, en el grupo de 25 a 34 años es donde más rotundamente se observa que esta dependencia se produce en función del género: los varones desempleados de esas edades siguen dependiendo de sus padres (en el 69 por 100 de los casos), mientras que las mujeres desempleadas de ese mismo grupo generacional han pasado a depender de un cónyuge o pareja (en el 66 por 100).

El hecho de que en estos hogares de los desempleados dependientes haya 
alguna persona ocupada (en uno de cada cuatro hay más de una) les ofrece una garantía de normalidad en la disposición de recursos económicos y evita que caigan en la precariedad que suele ir asociada a la situación de desempleo ${ }^{8}$. Así, el nivel de ingresos que se reconoce en estas unidades familiares es similar, si no superior, al que resulta en el conjunto de la población y, lo que es aún más significativo, dadas las dudas que despiertan habitualmente las respuestas acerca del nivel de ingresos, el 44 por 100 de los entrevistados califica su situación económica como igual que la de «la mayoría de las familias españolas», y hay un 20 por 100 que la juzga incluso mejor que la media (cuadro 16).

Aunque no sean espectaculares, sí se aprecian diferencias en la situación de los hogares según sea la relación de parentesco entre el individuo desempleado y el sustentador principal que se ocupa de aportar los ingresos al hogar. La mejor situación se da cuando el desempleado dependiente es el hijo o la hija de quien aporta los ingresos: la proporción de los que piensan en este caso que su situación es peor que la media (25 por 100) iguala a la de los que piensan que es mejor ( 25 por 100 ), y la calificación en la escala de 0 a 10 puntos alcanza un 4,9 , lo que equivale a un reconocimiento de que la situación de esas familias es similar a la de la mayoría de las familias españolas. Cuando el desempleado dependiente es cónyuge o pareja de la persona que aporta los ingresos al hogar, la situación es algo peor (con una media de 4,7 puntos en una escala de 0 a $10)$, y es peor aún cuando el sustentador principal tiene otra relación de parentesco distinta a las ya mencionadas (4,2 de media).

\section{CUADRO 16}

\section{Percepción subjetiva de la situación económica familiar}

\begin{tabular}{|c|c|c|c|c|}
\hline \multirow{2}{*}{$\begin{array}{c}\text { Situación económica } \\
\text { de la familia en relación } \\
\text { con la situación de la mayoría } \\
\text { de las familias del país }\end{array}$} & \multicolumn{4}{|c|}{ Relación con el sustentador principal } \\
\hline & $\begin{array}{l}\text { Cónyuge } \\
\text { o pareja }\end{array}$ & Hijola & $\begin{array}{l}\text { Otra } \\
\text { relación }\end{array}$ & Total \\
\hline Peor & 35 & 25 & 50 & 32 \\
\hline Igual & 44 & 46 & 36 & 44 \\
\hline Mejor & 18 & 25 & 11 & 20 \\
\hline NC & 3 & 4 & 3 & 4 \\
\hline 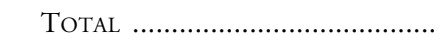 & 100 & 100 & 100 & 100 \\
\hline $\begin{array}{l}\text { Puntuación media* } \\
\text { (N) }\end{array}$ & $\begin{array}{l}4,7 \\
(984)\end{array}$ & $\begin{array}{l}4,9 \\
(806)\end{array}$ & $\begin{array}{c}4,2 \\
(149)\end{array}$ & $\begin{array}{r}4,7 \\
(1.995)\end{array}$ \\
\hline
\end{tabular}

* Ver nota bajo el cuadro 11.

8 Este hecho ya se había constatado en diversas investigaciones, realizadas con diferentes metodologías, en torno a la relación entre desempleo y familia (Iglesias de Ussel, 1995). 


\section{LOS DESEMPLEADOS DESAMPARADOS}

Casi uno de cada cuatro desempleados (el 22 por 100) se encuentra en una situación que cabe calificar de desamparo: no recibe cobertura social alguna por parte del sistema formal de protección que ofrece el INEM y tampoco en su entorno familiar hay persona alguna que esté trabajando y asuma, por consiguiente, la función de proveedora de los recursos necesarios para el hogar. Al dibujar el perfil de este tipo de desempleado se observa la extraordinaria importancia que adquiere la variable estado civil: son las personas no casadas — sean solteras, separadas, divorciadas o viudas - las que en mayor medida se encuentran en esta situación, especialmente los desempleados solteros que viven en un entorno no familiar, hasta el punto de que el 63 por 100 de ellos pueden ser calificados así. Por detrás se sitúan los solteros no demasiados jóvenes (entre 25 y 34 años) que viven en un entorno familiar y las personas separadas, divorciadas o viudas.

Por contra, las personas casadas (da igual que sean varones que mujeres) y los solteros muy jóvenes, de 16 a 24 años, que se supone que aún no han abandonado el hogar paterno, son los grupos que se encuentran más a salvo de esta situación de desamparo, como se puede observar en los resultados del análisis de segmentación que ofrece el cuadro 17.

\section{CUADRO 17}

Análisis de segmentación de los desempleados desamparados

\begin{tabular}{|c|c|c|c|}
\hline Caracteristicas del segmento & $(N)$ & $\begin{array}{l}\text { Porcentaje } \\
\text { que representa } \\
\text { el segmento } \\
\text { sobre la } \\
\text { población }\end{array}$ & $\begin{array}{c}\text { Porcentaje de } \\
\text { desempleados } \\
\text { desamparados } \\
\text { en el } \\
\text { segmento }\end{array}$ \\
\hline $\begin{array}{l}\text { Solteros que viven en un entorno no familiar ......... } \\
\text { Solteros que viven en un entorno familiar y tienen }\end{array}$ & $(143)$ & 3,1 & 63,3 \\
\hline 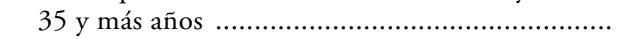 & $(274)$ & 5,9 & 43,8 \\
\hline Personas viudas, divorciadas o separadas ................. & $(293)$ & 6,3 & 38,8 \\
\hline $\begin{array}{l}\text { Solteros que viven en un entorno familiar y tienen } \\
\text { entre } 25 \text { y } 34 \text { años }\end{array}$ & $(640)$ & 13,7 & 31,6 \\
\hline Personas casadas con estudios superiores y más de 45 & $(87)$ & 1,9 & 20,5 \\
\hline $\begin{array}{l}\text { Jóvenes solteros de } 16 \text { a } 24 \text { años que viven en fa- } \\
\text { milia }\end{array}$ & $(801)$ & 17,2 & 20,1 \\
\hline Personas casadas con estudios primarios o inferiores ...... & $(972)$ & 20,9 & 17,3 \\
\hline Personas casadas con estudios de EGB o FP ........... & $(1.026)$ & 22,0 & 12,7 \\
\hline $\begin{array}{l}\text { Personas casadas con estudios superiores y menos de } \\
45 \text { años }\end{array}$ & $(165)$ & 3,5 & 8,4 \\
\hline Personas casadas con estudios medios $\ldots \ldots \ldots \ldots \ldots \ldots \ldots$ & $(256)$ & 5,5 & 7,4 \\
\hline
\end{tabular}


Aunque, como se ha señalado, el segmento más característico de este colectivo es el constituido por los solteros que viven fuera de un entorno familiar, lo cierto es que su dimensión es muy reducida y la mayoría de los desempleados desamparados (el 88 por 100) viven en el seno de una unidad familiar, frente a sólo un 12 por 100 que vive solo o en entornos no familiares. La diferencia en la forma de vida es importante por cuanto la disponibilidad de recursos depende de cuál sea ésta. Los desempleados que no reciben protección por parte del INEM y viven en un entorno no familiar dependen para su supervivencia de la ayuda de familiares o amigos que no conviven con ellos (en un 35 por 100 de los casos) o de ingresos procedentes de trabajos esporádicos (33 por 100); los datos muestran, sin embargo, que casi uno de cada tres de estos desempleados (el 31 por 100) parece encontrarse en una situación de suma precariedad, ya que no dispone de ningún ingreso de los que se recogen en el cuadro 18 .

La situación es bastante distinta en el caso de los desempleados desamparados que viven en un entorno familiar. Aunque ninguno de los miembros de ese hogar tenga una ocupación, en la mayoría de los casos existen ingresos procedentes de pensiones de algún miembro de la familia (55 por 100) o de ayudas por desempleo (prestaciones o subsidios) de algún otro miembro distinto al entrevistado (17 por 100) o de trabajos ocasionales realizados por el sujeto desempleado (20 por 100); en su conjunto, en el 86 por 100 de los hogares de los desempleados desamparados que viven en un entorno familiar se cuenta con algún tipo de ingreso, aunque sea más o menos precario.

El nivel de ingresos que reconocen estos desempleados también es diferente según vivan en un entorno familiar o no; los que viven en solitario se encuentran por debajo de las 50.000 pesetas mensuales como ingreso modal, mientras que los que viven en familia sitúan sus ingresos de forma mayoritaria en el intervalo de 50.001 a 100.000 pesetas. La sensación de precariedad económica de estos colectivos queda reflejada en la apreciación subjetiva de su situación, que es calificada generalmente como peor que la de «la mayoría de las familias de este país»; en una escala de 0 a 10 puntos, en la que el 5 vendría a ser un punto medio equivalente a la situación promedio de la economía de las familias, los desempleados desamparados que conviven en un entorno familiar puntúan su situación con un 3,9 y los que viven solos con un 3,6 . 


\section{CUADRO 18}

Ingresos en los hogares de los desempleados desamparados (Porcentaje de hogares que dispone de alguno de los siguientes ingresos)

\begin{tabular}{|c|c|c|c|}
\hline & Total & $\begin{array}{l}\text { Conviven } \\
\text { en un entorno } \\
\text { familiar }\end{array}$ & $\begin{array}{l}\text { Viven } \\
\text { en un entorno } \\
\text { no familiar }\end{array}$ \\
\hline $\begin{array}{l}\text { Pensiones de algún miembro de la familia ..... } \\
\text { Prestación o subsidio de desempleo de algún } \\
\text { otro miembro de la familia distinto al entre- } \\
\text { vistado }\end{array}$ & 50 & 55 & - \\
\hline $\begin{array}{l}\text { Becas o ayudas al estudio de algún miembro } \\
\quad \text { de la unidad familiar ............................... } \\
\text { Ayudas de Instituciones Públicas ................. } \\
\text { Ayudas de Instituciones Privadas .................. } \\
\text { Ayudas de familiares o amigos ..................... } \\
\text { Ingresos procedentes de trabajos ocasionales } \\
\text { realizados por el entrevistado }\end{array}$ & $\begin{array}{r}6 \\
6 \\
2 \\
15\end{array}$ & $\begin{array}{r}6 \\
6 \\
2 \\
12\end{array}$ & $\begin{array}{r}3 \\
5 \\
2 \\
35\end{array}$ \\
\hline 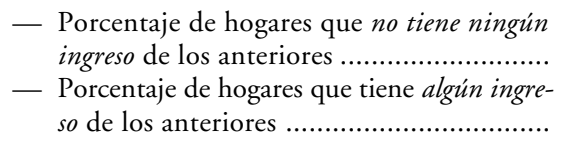 & 16 & 86 & 69 \\
\hline $\begin{array}{l}\text { TOTAL } \\
(\mathrm{N})\end{array}$ & $\begin{array}{c}100 \\
(1.034)\end{array}$ & $\begin{array}{c}100 \\
(912)\end{array}$ & $\begin{array}{c}100 \\
(121)\end{array}$ \\
\hline
\end{tabular}

\section{CUADRO 19}

Percepción subjetiva de los hogares de los desempleados desamparados

\begin{tabular}{|c|c|c|c|}
\hline $\begin{array}{l}\text { Situación económica de la familia } \\
\text { en relación con la situación de la mayoría } \\
\text { de las familias del país }\end{array}$ & Total & $\begin{array}{l}\text { Conviven } \\
\text { en un entorno } \\
\text { familiar }\end{array}$ & $\begin{array}{l}\text { Viven } \\
\text { en un entorno } \\
\text { no familiar }\end{array}$ \\
\hline 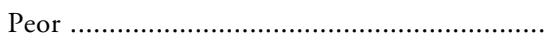 & 56 & 56 & 61 \\
\hline Igual & 32 & 32 & 28 \\
\hline 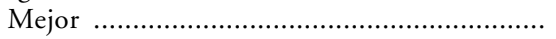 & 8 & 9 & 5 \\
\hline NC & 4 & 3 & 6 \\
\hline 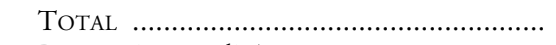 & 100 & 100 & 100 \\
\hline $\begin{array}{l}\text { Puntuación media* } \\
(\mathrm{N})\end{array}$ & $\begin{array}{r}3,8 \\
(1.037)\end{array}$ & $\begin{array}{l}3,9 \\
(912)\end{array}$ & $\begin{array}{l}3,6 \\
(121)\end{array}$ \\
\hline
\end{tabular}

* Ver nota bajo el cuadro 11. 


\section{RECAPITULACIÓN: LOS DIFERENTES NIVELES DE PRECARIEDAD ENTRE LOS DESEMPLEADOS}

Si hay algo que se ha puesto rotundamente de manifiesto al analizar las condiciones sociales de los desempleados en España es la extraordinaria heterogeneidad de las situaciones que caben dentro de la condición genérica del desempleo. Esta heterogeneidad de situaciones y circunstancias tiene que ver, principalmente, con el rol que el individuo desempleado desempeña en la unidad familiar como proveedor, sea principal o subsidiario, de recursos; como individuo dependiente, carente de la autonomía derivada de la disponibilidad de recursos propios, pero protegido por una estructura familiar que ejerce una función de "colchón" ante la situación de desempleo o como sujeto a la intemperie, al margen de los mecanismos formales de protección social y carente también de la protección que ejerce la institución familiar.

Al analizar la situación social y las condiciones de vida del individuo desempleado desde esta doble perspectiva de la protección formal que le ofrece el sistema de seguridad social y de la protección primaria que le garantiza la institución familiar, se advierte esa pluralidad de circunstancias que se ha venido analizando en las páginas anteriores y que queda reflejada de manera sintética en los datos del cuadro 20. En él se consideran hasta once tipos de desempleados, con niveles de protección diferentes y con circunstancias personales y familiares muy distintas entre sí, que a su vez pueden agruparse en tres niveles diferentes de precariedad en cuanto a la situación económica familiar que se infiere de los datos.

\section{Desempleados en situación económica precaria}

Son los desempleados incluidos en los cuatro primeros grupos del cuadro 20 y vienen a representar algo más del 30 por 100 de los inscritos en el INEM en el momento de realizarse la encuesta (casi 750.000 personas). Los datos obtenidos en cuanto a la disponibilidad de recursos en el hogar ya apuntaban a un cierta precariedad, pero, además, estos desempleados consideran que su situación económica familiar es significativamente peor que la media de las familias del país, con una calificación que se sitúa por debajo de los 4 puntos en una escala de 0 a 10 puntos. Entre estos desempleados en situación precaria se encuentran los siguientes colectivos, cuyos rasgos pueden ser claramente diferenciados:

1. Los desempleados que cobran subsidio asistencial y no disponen de ningún otro ingreso en el hogar, lo que significa que el individuo desempleado se ve obligado a desempeñar el rol de proveedor único del hogar a pesar de los escasos ingresos de que dispone (algo menos de 50.000 pesetas), para una unidad familiar que tiene como tamaño modal tres miembros. Se trata de un grupo 
reducido de desempleados (el 3,6 por 100 de los inscritos), pero con unos perfiles muy definidos: fundamentalmente se trata de varones no solteros (es decir, casados, separados, divorciados o viudos) de 450 más años de edad. Aunque no en la misma medida, también se encuentran sobrerrepresentados en este grupo los varones no solteros de menos de 45 años y las mujeres separadas, divorciadas o viudas.

2. Los desempleados que cobran subsidio asistencial y disponen de algún otro ingreso en el hogar, de carácter más o menos precario o esporádico, ya que no hay ninguna persona que trabaje, por lo que esos ingresos proceden de pensiones o ayudas externas al hogar. Ello significa que, a pesar de esos ingresos añadidos, el individuo desempleado sigue desempeñando el rol de principal proveedor de un hogar con un tamaño modal de 4 miembros, para los que se dispone de unos ingresos (también modales) que se sitúan entre 50.001 y 100.000 pesetas mensuales. Si el género y el estado civil definían el perfil de los desempleados incluidos en el grupo anterior, en este caso es la edad la variable fundamental: los desempleados de más de 45 años, especialmente los no casados, sean varones o mujeres, y los varones entre 25 y 44 años con estudios primarios o menos son los que en mayor medida integran este grupo.

3. Los desempleados que no cobran ningún tipo de ayuda y viven en un entorno no familiar son los que disponen de un menor nivel de ingresos (por debajo de 50.000 pesetas), lo que se ve compensado por el hecho de tener menos responsabilidades proveedoras, ya que carecen de entorno familiar, y ello explica que no se vean a sí mismos como los que están en peor situación (el índice es 3,6, frente al 3,5 de los grupos anteriores). Se trata de un grupo muy minoritario (menos del 3 por 100 de los desempleados), como es minoritaria la situación de vivir al margen de un entorno familiar, pero con unos rasgos demográficos muy definidos: se trata de personas no casadas - solteras, separadas, divorciadas o viudas-que tienen más de 45 años o, en menor medi$\mathrm{da}$, solteros entre 25 y 44 años.

4. El grupo más numeroso, con diferencia, dentro de estos desempleados que se caracterizan por la precariedad de su situación lo constituyen los que no cobran ningún tipo de ayuda procedente de los mecanismos formales de protección social y viven en un entorno familiar en el que no hay ninguna persona ocupada. Ello significa que el desempleado, que no dispone de ingresos, no es el sustentador principal del hogar, pero los ingresos que aporta quien asume esa función proveedora también tienen un cierto componente de precariedad, ya que proceden de pensiones, subsidios, ayudas o trabajos esporádicos e irregulares. Casi medio millón de desempleados inscritos en el INEM en el otoño de 1996, cuando se realizó la encuesta, respondían a estas características, lo que significa casi uno de cada cinco. Esta proporción se eleva especialmente entre los desempleados no casados de 25 a 44 años y entre los que tienen de 16 a 24 años y estudios primarios; también, en menor grado, entre las mujeres casadas con estudios primarios se encuentra este tipo de desempleo. 


\section{Desempleados protegidos}

Los desempleados incluidos en esta categoría alcanzan unos índices de precariedad que se sitúan entre 4 y 4,5; ello significa que consideran que su situación económica es peor que la de la mayoría de las familias del país, pero no mucho peor: al analizar con mayor detalle la composición de estos grupos se advierte que son colectivos que se encuentran significativamente más protegidos que los incluidos en el epígrafe anterior y que, en consecuencia, disponen también de un nivel de ingresos más elevado para la unidad familiar. En cuanto a su peso sobre el conjunto de desempleados, es más reducido que el que representaban los desempleados en situación precaria y también muy inferior al que tienen los desempleados dependientes que se analizarán más adelante: apenas 400.000 desempleados, el 16 por 100 de los inscritos en el INEM como demandantes de empleo, se incluyen en esta categoría, a la que pertenecen los siguientes grupos:

5. Desempleados que cobran algún tipo de protección (sea prestación contributiva o subsidio asistencial) y viven en un hogar en el que hay alguna persona que trabaja, aunque esta persona ocupada aporta al hogar menos ingresos que el desempleado. Se trata, pues, de desempleados que gracias a la protección que perciben (78,4 miles de pesetas, en promedio) desempeñan las funciones de proveedor principal, aunque los ingresos del hogar se vean «redondeados» con la aportación de alguna otra persona que trabaja regularmente pero que aporta una cantidad bastante escasa de recursos. El perfil que más se repite en este tipo es el de los varones casados de más de 45 años.

6. Desempleados que cobran la prestación contributiva y viven en un hogar en el que no hay ningún otro ingreso. Aunque el individuo desempleado se ve obligado a desempeñar el papel de proveedor exclusivo del hogar, la prestación media que recibe se sitúa casi en las 100.000 pesetas mensuales, duplicando el importe del subsidio asistencial por desempleo; si a ello se añade el hecho de que el tamaño de estos hogares es más reducido (dos miembros, como moda), la conclusión que cabe extraer es que el nivel de protección de que disfrutan les permite eludir la situación de precariedad que afectaba a los grupos analizados más arriba. El perfil sociodemográfico de este tipo de desempleado es rotundamente claro: en su gran mayoría se trata de varones casados.

7. Otro grupo de desempleados lo constituyen los que no perciben ningún ingreso y viven en un hogar en el que el proveedor principal no es ni su cónyuge ni su progenitor. Además de ser un grupo reducido (el 3 por 100 de los desempleados), es bastante atípico y resulta un ejemplo extremo de la utilización de la familia como colchón de protección ante la situación de desempleo, incluso más allá del núcleo constituido por los padres y los hijos: en este caso el proveedor principal es hermano, cuñado, yerno, etc., del individuo que se encuentra en situación de desempleo y convive en el hogar familiar. El estado civil es el principal rasgo que define a estos desempleados, que tienden a ser en mayor medida solteros, separados o divorciados. 
8. Desempleados que perciben la prestación contributiva y conviven en un hogar en el que hay, además, otros ingresos que no proceden de un trabajo regular, sino de pensiones, subsidios u otro tipo de ayudas. Ello provoca que el desempleado sea el proveedor principal de recursos del hogar, pero el complemento que aportan otros ingresos permite afrontar la situación sin caer en la precariedad. Los varones de más de 25 años y las mujeres solteras, separadas o divorciadas de más de 35 suelen estar más representados en este tipo particular de desempleados.

\section{Desempleados desahogados}

Más de la mitad de los desempleados inscritos en el INEM en el otoño de 1996 (lo que significa algo más de 1.200 .000 desempleados) viven en hogares donde hay otra $u$ otras personas que trabajan $y$, por consiguiente, asumen la función proveedora de recursos para la unidad familiar. Los desempleados que viven en estas circunstancias no se caracterizan por una situación de precariedad, sino, en todo caso, de dependencia respecto de la persona que aporta esos recursos al hogar; al ser consultados acerca de la situación económica de su hogar en relación con la del común de los hogares españoles, le atribuyen unos índices que se sitúan entre 4,5 y 5 , es decir, muy cerca de lo que consideran que es la situación media de las familias de este país. Entre estos desempleados se pueden distinguir, no obstante, tres grupos bien diferenciados:

9. Desempleados que no tienen ingresos y viven en un hogar en el que el proveedor principal es su cónyuge o pareja. Este grupo representa más de medio millón de desempleados, la mayoría de los cuales son mujeres casadas. De hecho, el 57 por 100 de las mujeres casadas que se encuentran en situación de desempleo se ubican en este tipo concreto, lo que les pone en una situación clara de dependencia económica respecto del marido. A la inversa, sólo un 12 por 100 de los varones casados desempleados depende económicamente de los ingresos aportados al hogar por el trabajo de su esposa.

10. Desempleados que perciben algún tipo de protección (algo menos de 70.000 pesetas en promedio) pero no son los principales proveedores del hogar, ya que hay alguna otra persona que trabaja en el hogar y aporta más ingresos que el desempleado. Se trata de proveedores subsidiarios de la unidad familiar, cuya disponibilidad de recursos vienen a completar. De nuevo las mujeres casadas, en este caso con estudios medios o superiores, son las que están más representadas en este colectivo.

11. Desempleados que no tienen ingresos y viven en un hogar en el que el proveedor principal es un progenitor, generalmente el padre. Se trata mayoritariamente de jóvenes que siguen viviendo en una situación de dependencia económica en el hogar familiar. Al definir el perfil de este tipo de desempleado se advierte que, a diferencia de los anteriores, el género no tiene ninguna influencia; son el estado civil, la edad y el nivel educativo las variables que definen a este tipo de desempleados: los jóvenes entre 16 y 24 años, solteros y con estudios por encima de primarios son quienes constituyen mayoritariamente este grupo. 


\section{CUADRO 20}

Taxonomía de los desempleados, según su nivel de precariedad

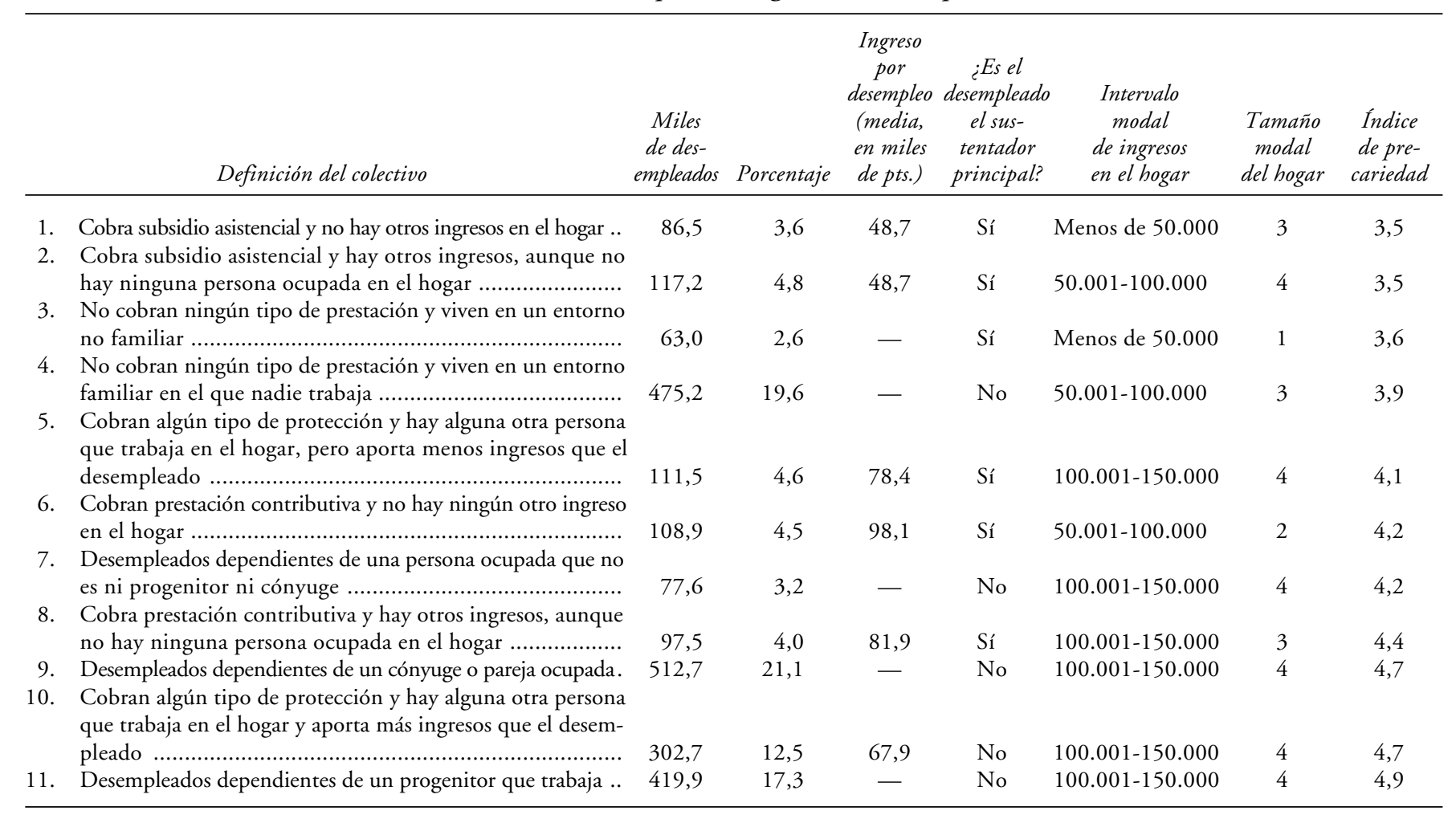




\section{CONCLUSIONES}

1. En un país como España, afectado por altas tasas de paro y con un sistema de protección social por desempleo que no alcanza una cobertura universal, las condiciones de vida de la población desempleada se encuentran especialmente asociadas al rol que el individuo en esta situación viene desempeñando en el seno de la unidad familiar en la que se integra.

2. De manera análoga a las teorías sobre una creciente segmentación del mercado de trabajo entre un "núcleo» de trabajadores que se caracterizan por disponer de un alto grado de protección social y una notable estabilidad en el empleo y una "periferia" caracterizada cada vez en mayor medida por la precariedad y la temporalidad, entre la población desempleada se constata la existencia de un segmento protegido, que coincide con el que asume las funciones proveedoras de la unidad familiar, y otro dependiente que, situado al margen de la cobertura que ofrece el Estado del Bienestar, encuentra en la institución familiar el mecanismo de protección que le permite afrontar la situación de desempleo.

3. El género, la edad y el estado civil determinan en gran medida la pertenencia a uno u otro segmento de la población desempleada. Los varones adultos casados, sobre cuya atribución de responsabilidades proveedoras se ha articulado el mecanismo de cobertura social por desempleo, constituyen el núcleo protegido por el sistema. Sin embargo, la protección que reciben por parte del Estado del Bienestar resulta escasamente suficiente para afrontar las responsabilidades proveedoras de la unidad familiar que se le siguen exigiendo al varón adulto casado, incluso en la situación de desempleo.

4. Los jóvenes solteros y las mujeres casadas constituyen el grueso de los segmentos que quedan al margen de los mecanismos formales de protección y para los que la institución familiar constituye el único amparo. Ello conlleva una clara situación de dependencia, en un caso generacional - los hijos desempleados que siguen dependiendo de los recursos aportados por los padres en cuyo hogar conviven - y en el otro conyugal — las mujeres casadas desempleadas que dependen de los recursos aportados al hogar por el marido que trabaja-, pero, en contrapartida, estos hogares donde el principal proveedor de recursos para el hogar es una persona ocupada no viven la situación de precariedad que caracteriza a los hogares en los que el desempleado se ve obligado a ejercer de proveedor. 


\title{
REFERENCIAS
}

Coller i Porta, X. (1991): "Roles familiares y mercado de trabajo», Papers. Revista de Sociologia, 36: 93-114.

ESPING-ANDERsEN, G. (1993): Los tres mundos del Estado del Bienestar, Valencia, Edicions Alfons el Magnànim.

- (1995): Welfare states without work: the impasse of labor shedding and familialism in continental european social policy, Madrid, Instituto Juan March de Estudios e Investigaciones, Working Papers 1995/71.

Garrido MedinA, L. (1993): «La familia estatal: el control fiscal de la natalidad», en L. Garrido Medina y E. Gil Calvo (eds.), Estrategias familiares, Madrid, Alianza Editorial.

Garrido, L., y Requena, M. (1996): La emancipación de los jóvenes en España, Madrid, Instituto de la Juventud.

Guillén, A. M. (1997): "Regímenes de bienestar y roles familiares: un análisis del caso español», Papers. Revista de Sociología, 53: 45-63.

IgLesias DE UsSel, J. (1995): "Trabajo y familia en España», Revista Internacional de Sociología, 11: 171-198.

TOHARIA CorTés, L. (1993): «La incidencia familiar del paro», en L. Garrido Medina y E. Gil Calvo (eds.), Estrategias familiares, Madrid, Alianza Editorial.

VAliEnTE, C. (1998): «Género, mercado de trabajo y Estado de Bienestar», Sociología del Trabajo, 32: 53-80.

\begin{abstract}
This research paper aims to establish a typology of Spain's unemployed, taking note of two key dimensions in terms of understanding the problem: the position of the unemployed in the face of the protection mechanisms generated by the welfare state and the role played by the unemployed in the family unit. The result is a classification of the unemployed in the following categories: suppliers, co-suppliers, the defenceless and the dependent, which denotes the obvious inequality which exists in terms of access to the mechanisms of social protection. The conclusion which can be drawn is that the model of the welfare state prevailing in Spanish society plays a role which is subsidiary to what continues to be the main mechanism of social solidarity: the family institution.
\end{abstract}

